\title{
Plasma procalcitonin and risk of type 2 diabetes in the general population
}

\author{
A. Abbasi • E. Corpeleijn • D. Postmus • R. T. Gansevoort • P. E. de Jong • \\ R. O. B. Gans • J. Struck • H. L. Hillege • R. P. Stolk • G. Navis • S. J. L. Bakker
}

Received: 19 January 2011 / Accepted: 20 May 2011 /Published online: 15 June 2011

(C) Springer-Verlag 2011

Keywords Procalcitonin $\cdot$ Risk factor. Type 2 diabetes

\begin{abstract}
Abbreviations
hs-CRP High sensitivity C-reactive protein

IDI Integrated discrimination improvement

IQR Interquartile range
\end{abstract}

To the Editor: Chronic low-grade inflammation is a key feature of the pathophysiology of obesity, insulin resistance and type 2 diabetes [1]. In vitro studies have found that parenchymal cells of tissues, including adipocytes, secrete procalcitonin in response to stimulation by activated macrophages [2]. Since obesity is associated with an

Electronic supplementary material The online version of this article (doi:10.1007/s00125-011-2216-3) contains peer-reviewed but unedited supplementary material, which is available to authorised users.

A. Abbasi $(\bowtie) \cdot$ E. Corpeleijn $\cdot$ D. Postmus $\cdot$ H. L. Hillege $\cdot$

R. P. Stolk

Department of Epidemiology, University Medical Center

Groningen, University of Groningen,

Hanzeplein 1, P.O. Box 30.001, 9700 RB Groningen,

the Netherlands

e-mail: a.abbasi@epi.umcg.nl

A. Abbasi - R. T. Gansevoort - P. E. de Jong • R. O. B. Gans •

G. Navis $\cdot$ S. J. L. Bakker

Department of Internal Medicine,

University Medical Center Groningen, University of Groningen,

Groningen, the Netherlands

J. Struck

Department of Research,

BRAHMS GmbH (Part of Thermo Fisher Scientific),

Hennigsdorf, Germany increased presence of activated macrophages in adipose tissue, a similar scenario may play a role in vivo $[2,3]$. In an initial study, we found that procalcitonin is associated with insulin resistance and all components of the metabolic syndrome [3]. Our current aim is to test the prospective association of plasma procalcitonin with incident type 2 diabetes in the general population, and to compare its predictive value with that of high sensitivity C-reactive protein (hs-CRP).

The study population was obtained from the Prevention of Renal and Vascular End-stage Disease (PREVEND) study, Groningen, the Netherlands. Details of the study design, recruitment and measurements have been published elsewhere [3, 4]. Of 8,592 participants in this cohort, the procalcitonin value was missing in 677 individuals. Further exclusion was for 295 individuals with diabetes at baseline and 1,002 individuals with missing data on covariates or follow-up data on development of diabetes. The current analyses were performed on 6,618 non-diabetic participants with complete data. In baseline samples, plasma procalcitonin was measured by a novel commercially available immuno-luminometric assay (BRAHMS PCT sensitive LIA; BRAHMS, Hennigsdorf, Germany). Assays were performed in EDTA-plasma aliquots that had been stored frozen at $-80^{\circ} \mathrm{C}$, without prior thawing and re-freezing. The intra-assay $\mathrm{CV}$ was $6 \%$ at $0.1 \mathrm{ng} / \mathrm{ml}$ and $8 \%$ at $0.03 \mathrm{ng} / \mathrm{ml}$. The functional assay sensitivity, defined as the lowest concentration to be determined with an interassay $\mathrm{CV}$ of $20 \%$, was $0.007 \mathrm{ng} / \mathrm{ml}$ and lowest detection limit was $0.006 \mathrm{ng} / \mathrm{ml}$. The assay technique for procalcitonin and other biomarkers has been described previously [3, 5].

Incident type 2 diabetes was ascertained if one or more of the following conditions were met: self-report of physi- 
cian diagnosis; fasting plasma glucose of $\geq 7.0 \mathrm{mmol} / \mathrm{l}$; random sample plasma glucose $\geq 11.1 \mathrm{mmol} / 1$; use of glucose-lowering agents according to a central pharmacy registration.

We applied logistic regression models to test the associations of procalcitonin and hs-CRP with incident diabetes. To assess the added value of procalcitonin and hs$\mathrm{CRP}$, we examined improvement of diabetes prediction in terms of C-statistic, a measure of discrimination, and integrated discrimination improvement (IDI), a measure of reclassification. A $p$ value of $\leq 0.05$ from two-sided tests was considered statistically significant. The statistical analyses were performed using SPSS 18.0 (SPSS, Chicago, IL, USA) and R version 2.11.0 (Vienna, Austria) (http:// cran.r-project.org/).

The median (interquartile range [IQR]) of plasma procalcitonin was $0.016(0.013-0.020) \mathrm{ng} / \mathrm{ml}$; men had a higher level than women. Anthropometric and clinical characteristics are summarised in the electronic supplementary material (ESM) Table 1. Participants with higher procalcitonin levels were older, more obese and had higher hs-CRP (correlation coefficient 0.24; $p<0.001$ ) (ESM Fig. 1).

During follow-up for $7.6 \pm 0.8$ years (mean $\pm \mathrm{SD}$ ), 385 participants developed type 2 diabetes. Median (IQR) procalcitonin levels were $0.019(0.015-0.023)$ and 0.016 $(0.013-0.019) \mathrm{ng} / \mathrm{ml}$ in incident cases and non-cases, respectively $(p<0.001)$. ORs for incident type 2 diabetes by quartiles of procalcitonin and hs-CRP are presented in Table 1. A graded increase in risk was observed in crude analysis, after adjustment for age, sex, smoking and alcohol intake (model 2), and additional adjustment for hypertension and parental history of diabetes (model 3) $(p<0.001)$. In model 4 , with further adjustment for BMI and waist circumference, the OR for incident type 2 diabetes in the fourth quartile of procalcitonin was $1.74(95 \%$ CI 1.13, 2.68) compared with the lowest quartile ( $p=0.008)$. The association of hs-CRP lost significance with this further adjustment (Table 1). In a secondary analysis, the association of procalcitonin with incident type 2 diabetes remained significant after adjustment for HDL-cholesterol (OR 1.25; 95\% CI 1.01, 1.53; $p=0.04)$.

C-statistic improved from $0.78(0.76-0.81)$ to 0.79 $(0.77-0.81)(p=0.05)$ and IDI was $0.0025(p=0.02)$ after adding procalcitonin to a clinical prediction model including sex, smoking, waist circumference, hypertension and family history of diabetes [6]. We observed no improvement in C-statistic $(p=0.23)$ or IDI $(p=0.35)$ when hs-CRP was added instead of procalcitonin.

Table 1 ORs $(95 \%$ CI) for incident type 2 diabetes by quartiles of plasma procalcitonin and hs-CRP $(n=6,618)$

\begin{tabular}{|c|c|c|c|c|c|c|c|}
\hline \multirow[t]{2}{*}{ Variable } & \multicolumn{5}{|c|}{ Quartile } & \multirow{2}{*}{$\begin{array}{l}\text { OR }(95 \% \text { CI }) \text { per } \\
\text { Log }_{2} \text {-unit increase }\end{array}$} & \multirow[t]{2}{*}{$p$ value } \\
\hline & 1 & 2 & 3 & 4 & $p$ value for trend & & \\
\hline \multicolumn{8}{|l|}{ Procalcitonin } \\
\hline $\begin{array}{l}\text { Incidence rate per } 1,000 \\
\text { person-years }\end{array}$ & 3.0 & 6.0 & 7.2 & 13.7 & & & \\
\hline Crude analysis & 1.00 & $2.00(1.31,3.05)$ & $2.41(1.59,3.65)$ & $4.80(3.23,7.12)$ & $<0.001$ & $1.86(1.58,2.19)$ & $<0.001$ \\
\hline Model 1 & 1.00 & $1.70(1.11,2.60)$ & $1.67(1.09,2.56)$ & $2.91(1.92,4.42)$ & $<0.001$ & $1.50(1.26,1.79)$ & $<0.001$ \\
\hline Model 2 & 1.00 & $1.68(1.10,2.57)$ & $1.64(1.07,2.52)$ & $2.85(1.88,4.34)$ & $<0.001$ & $1.50(1.26,1.79)$ & $<0.001$ \\
\hline Model 3 & 1.00 & $1.64(1.07,2.52)$ & $1.58(1.03,2.43)$ & $2.59(1.70,3.96)$ & $<0.001$ & $1.45(1.21,1.72)$ & $<0.001$ \\
\hline Model 4 & 1.00 & $1.45(0.93,2.24)$ & $1.18(0.76,1.83)$ & $1.74(1.13,2.68)$ & 0.008 & $1.32(1.09,1.60)$ & 0.004 \\
\hline \multicolumn{8}{|l|}{ hs-CRP } \\
\hline $\begin{array}{l}\text { Incidence rate per } 1,000 \\
\text { person-years }\end{array}$ & 2.6 & 5.7 & 9.5 & 12.0 & & & \\
\hline Crude analysis ${ }^{\mathrm{b}}$ & 1.00 & $2.22(1.45,3.40)$ & $3.79(2.55,5.64)$ & $4.83(3.27,7.13)$ & $<0.001$ & $1.38(1.29,1.48)$ & $<0.001$ \\
\hline Model 1 & 1.00 & $1.83(1.19,2.81)$ & $2.79(1.86,4.18)$ & $3.55(2.38,5.29)$ & $<0.001$ & $1.30(1.21,1.40)$ & $<0.001$ \\
\hline Model 2 & 1.00 & $1.79(1.16,2.75)$ & $2.68(1.78,4.02)$ & $3.33(2.22,4.98)$ & $<0.001$ & $1.28(1.19,1.38)$ & $<0.001$ \\
\hline Model 3 & 1.00 & $1.66(1.08,2.56)$ & $2.38(1.58,3.58)$ & $2.91(1.94,4.39)$ & $<0.001$ & $1.25(1.16,1.35)$ & $<0.001$ \\
\hline Model 4 & 1.00 & $1.21(0.78,1.88)$ & $1.44(0.94,2.19)$ & $1.42(0.92,2.19)$ & 0.26 & $1.06(0.97,1.16)$ & 0.16 \\
\hline
\end{tabular}

Plasma procalcitonin quartiles $(\mathrm{ng} / \mathrm{ml}): 1, \leq 0.012 ; 2,0.013-0.015 ; 3,0.016-0.019 ; 4, \geq 0.020$; hs-CRP quartiles $(\mathrm{mg} / 1): 1, \leq 0.54 ; 2,0.54-1.18 ; 3$, $1.19-2.76 ; 4, \geq 2.77$

Model 1 is adjusted for age and sex; model 2 is adjusted for variables in model 1 plus alcohol use and smoking status; model 3 is adjusted for variables in model 2 plus hypertension and parental history of diabetes; model 4 is adjusted for variables in model 3 plus body mass index and waist circumference

${ }^{\text {a }}$ OR expressed per unit increase in $\log _{2}$-transformed level of procalcitonin and hs-CRP

${ }^{\mathrm{b}}$ Analyses based on a sample of participants with data on hs-CRP ( $n=6,393$ [361 incident cases]) 
We found plasma procalcitonin to be an independent predictor of incident type 2 diabetes in the general population. In particular, plasma procalcitonin was more strongly associated with incident type 2 diabetes than hsCRP after accounting for adiposity.

The link between obesity and diabetes is mediated through both low-grade inflammation and noninflammatory processes $[1,7]$. In our data, adjustment for adiposity attenuated the association of procalcitonin with type 2 diabetes risk. This supports the notion that obesity partly contributes to this association. Further contribution might be made by adipocyte dysfunction, other inflammatory conditions or lipid markers, rather than adipose tissue mass [3]. In line with previous evidence [7], the association between hs-CRP and type 2 diabetes lost significance after accounting for adiposity. This suggests that procalcitonin as a pro-inflammatory predictor of type 2 diabetes may be more independent of obesity than hs-CRP.

Our findings suggest that the calcitonin-related system may play a role in the pathophysiology of diabetes. Experimental studies have demonstrated biological activity of procalcitonin on calcitonin receptor family complexes, affecting vascular tone, insulin sensitivity and insulin secretion by the pancreatic beta cells $[2,8]$.

Some limitations of this study should be noted. As our study only recruited White people in the Netherlands, it is unclear if our findings would be replicable in other populations. Another limitation concerned excluded individuals with missing data or without confirmed fasting blood sampling. However, only numerically small differences in baseline characteristics were found between those who included in the study and the excluded individuals. Moreover, we had no data on other inflammatory markers such as interleukin 6 or new diabetes risk factors such as $\gamma$-glutamyl transferase to compare their predictive value for type 2 diabetes with that of procalcitonin.

In conclusion, plasma procalcitonin levels are associated with incident type 2 diabetes independent of common diabetes risk factors. Our findings may be considered an opening for further studies on a potential role of the calcitonin-related system in the pathophysiology of diabetes.

Acknowledgements This work was supported by the Netherlands Heart Foundation, Dutch Diabetes Research Foundation and Dutch Kidney Foundation. This research was performed within the framework of the Center for Translational Molecular Medicine (CTMM) (www.ctmm.nl) project PREDICCt (grant 01C-104-07).
A.A. contributed to conception, design, analysis and interpretation of data, and drafted and revised the article. E.C. contributed to conception and interpretation of data and revised the article. D.P. contributed to analysis and interpretation of data and revised the article. R.T.G. contributed to interpretation of data and revised the article. P.E.de J. contributed to interpretation of data and revised the article. R.O.B.G. contributed to interpretation of data and revised the article. J.S. contributed to interpretation of data and revised the article. H.L.H. contributed to interpretation of data and revised the article. R.P.S. contributed to conception and interpretation of data and revised the article. G.N. contributed to conception and interpretation of data and revised the article. S.J.L.B. contributed to conception, design and interpretation of data, and drafted and revised the article. All authors contributed to final approval of the version to be published.

Duality of interest J. Struck is an employee of BRAHMS, a company that manufactures the procalcitonin assay and holds patent rights on procalcitonin. The present study was not financed by BRAHMS. No other author has anything to declare. None of the study sponsors had a role in study design, data collection, analysis or interpretation, or in writing the report or in the decision to submit for publication.

\section{References}

1. Wellen KE, Hotamisligil GS (2005) Inflammation, stress, and diabetes. J Clin Invest 115:1111-1119

2. Becker KL, Nylén ES, White JC, Müller B, Snider RH Jr (2004) Clinical review 167: procalcitonin and the calcitonin gene family of peptides in inflammation, infection, and sepsis: a journey from calcitonin back to its precursors. J Clin Endocrinol Metab 89:15121525

3. Abbasi A, Corpeleijn E, Postmus D et al (2010) Plasma procalcitonin is associated with obesity, insulin resistance, and the metabolic syndrome. J Clin Endocrinol Metab 95:E26-E31

4. Lambers Heerspink HJ, Brantsma AH, de Zeeuw D et al (2008) Albuminuria assessed from first-morning-void urine samples vs 24hour urine collections as a predictor of cardiovascular morbidity and mortality. Am J Epidemiol 168:897-905

5. Morgenthaler NG, Struck J, Fischer-Schulz C, Seidel-Mueller E, Beier W, Bergmann A (2002) Detection of procalcitonin (PCT) in healthy controls and patients with local infection by a sensitive ILMA. Clin Lab 48:263-270

6. Balkau B, Lange C, Fezeu L et al (2008) Predicting diabetes: clinical, biological, and genetic approaches: data from the Epidemiological Study on the Insulin Resistance Syndrome (DESIR). Diabetes Care 31:2056-2061

7. Lee CC, Adler AI, Sandhu MS et al (2009) Association of Creactive protein with type 2 diabetes: prospective analysis and meta-analysis. Diabetologia 52:1040-1047

8. Martínez A, Kapas S, Miller MJ, Ward Y, Cuttitta F (2000) Coexpression of receptors for adrenomedullin, calcitonin generelated peptide, and amylin in pancreatic beta-cells. Endocrinology $141: 406-411$ 